\title{
BMJ Open Quality Interprofessional education model for geriatric falls risk assessment and prevention
}

To cite: Brown DK, Fosnight S, Whitford M, et al. Interprofessional education model for geriatric falls risk assessment and prevention. BMJ Open Quality 2018;7:e000417. doi:10.1136/ bmjoq-2018-000417

Received 12 May 2018 Revised 28 September 2018 Accepted 12 October 2018
Check for updates

(c) Author(s) (or their employer(s)) 2018. Re-use permitted under CC BY-NC. No commercial re-use. See rights and permissions. Published by BMJ.

For numbered affiliations see end of article.

Correspondence to Dr Diane K Brown; dbrown1@uakron.edu

\section{ABSTRACT}

Background One in three people over the age of 65 fall every year, with $1 / 3$ sustaining at least moderate injury. Falls risk reduction requires an interprofessional health team approach. The literature is lacking in effective models to teach students how to work collaboratively in interprofessional teams for geriatric falls prevention. The purpose of this paper is to describe the development, administration and outcome measures of an education programme to teach principles of interprofessional care for older adults in the context of falls prevention.

Methods Students from three academic institutions representing 12 health disciplines took part in the education programme over 18 months $(n=237)$.

A mixed method one-group pretest and post-test experimental design was implemented to measure the impact of a multistep education model on progression in interprofessional collaboration competencies and satisfaction.

Results Paired $t$-tests of pre-education to posteducation measures of Interprofessional Socialization and Valuing Scale scores $(n=136)$ demonstrated statistically significant increase in subscales and total scores $(p<0.001)$. Qualitative satisfaction results were strongly positive. Discussion Results of this study indicate that active interprofessional education can result in positive student attitude regarding interprofessional team-based care, and satisfaction with learning. Lessons learnt in a rapid cycle plan-do-study-act approach are shared to guide replication efforts for other educators.

Conclusion Effective models to teach falls prevention interventions and interprofessional practice are not yet established. This education model is easily replicable and can be used to teach interprofessional teamwork competency skills in falls and other geriatric syndromes.

\section{INTRODUCTION}

Healthcare is provided by multidisciplinary teams of individuals, but until recent years there has been little emphasis on formal teamwork training to help these individuals function effectively together. Quality and safety in healthcare have been rightfully in the spotlight for nearly two decades since the release of To Err is Human. ${ }^{1}$ This report revealed the staggering amount of medical errors in the
USA and called for systematic change to make healthcare safer. One proposed solution was to advance training efforts for building teamwork competencies among health providers to address problems that stem from the fragmented healthcare system. Since then, there has been increased interest and an interprofessional teamwork movement in healthcare education and practice settings.

An area where team-based care can make a positive impact is in the care of the growing geriatric population. Delivery of effective healthcare for older adults is often complex due to the interplay between physical, social and emotional changes associated with ageing. Since over two thirds of Medicare beneficiaries have two or more chronic medical conditions, ${ }^{2}$ it is common to see a largely medical approach to their care. However, it is well established in the geriatric literature that it is the combination of chronic conditions coupled with functional impairment and geriatric syndromes that truly drive poor outcomes in this population. This complexity makes it especially important for the healthcare team to take an interprofessional team approach. Without a diverse set of providers working together as a team, fragmentation can result, leading to patient dissatisfaction, an ineffective plan of care and low-quality outcomes. However, effective teamwork is not innate to healthcare; it must be learnt and developed over time through purposeful education.

\section{Review of the literature}

The literature on team training supports active learning pedagogies such as simulation for building teamwork competency for interprofessional collaborative practice. $^{3}$ Demonstrations of effective interprofessional training models with progressive layers of learning experiences are lacking in the 


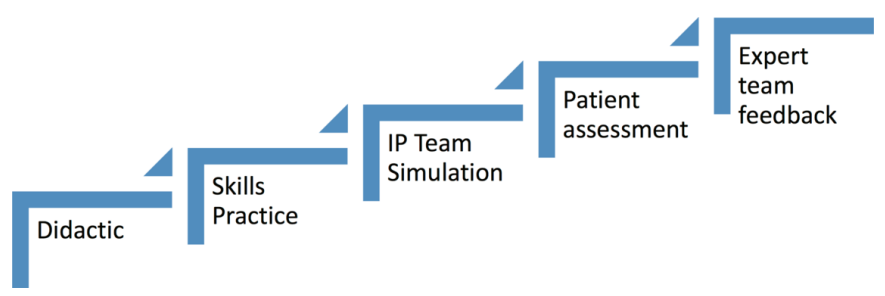

Figure 1 Education model.

literature. Many examples of interprofessional education (IPE) and team training rely solely on didactic and/or simulations which have revealed mixed effectiveness on education outcomes. ${ }^{4}$ This gap in the literature led us to develop our own education model using active learning methods including interprofessional simulation.

\section{Purpose}

The purpose of this paper is to describe the development, administration and outcome measures of an education programme to teach principles of interprofessional care for older adults in the context of falls prevention which resulted from ongoing rapid-cycle plan-do-study-act (PDSA) quality improvement processes.

\section{Theoretical framework}

Constructivism learning theory is the basis for simulation education, which served as the theoretical framework for designing an IPE model. ${ }^{5}$ Active learning such as simulation provides learners with authentic experiences that become cognitive frames for application in actual clinical practice. When education of adult learners is designed by scaffolding of experiences that build on one another, foundational knowledge is built on with skills practice and more complex application activities leading to the more complex outcome of competency. ${ }^{6}$

\section{DESIGN OF AN INTERPROFESSIONAL EDUCATION (IPE) MODEL}

We describe here an education model for team training that contains multiple layers of experiences building towards an interprofessional team simulation and application to actual practice (figure 1). Our interprofessional

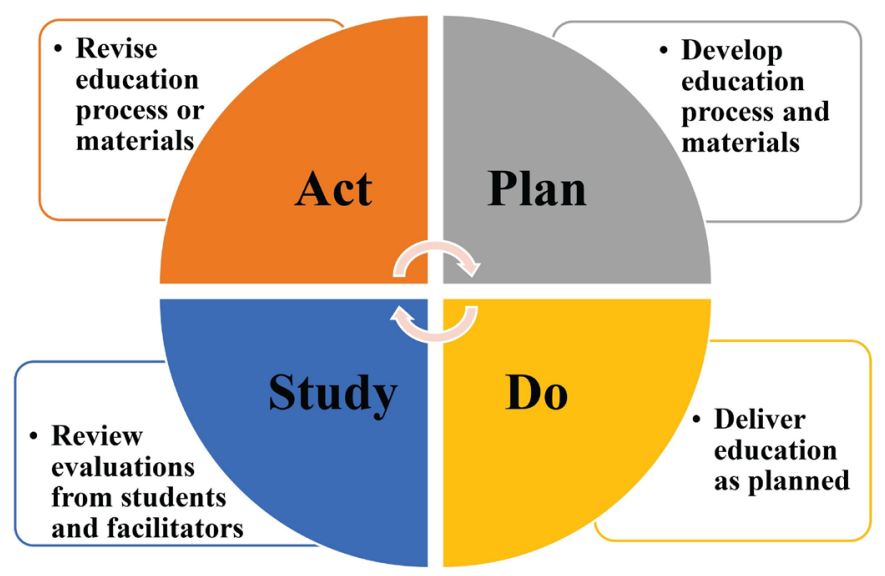

Figure 2 PDSA model. PDSA, plan-do-study-act. team of educators and clinicians designed each step to engage students in active learning that guides them towards learning outcomes of gaining Interprofessional Education Collaboration (IPEC) core competencies. ${ }^{7}$

\section{PDSA process}

Our grant team used the process of rapid cycle PDSA to assess and improve the quality of our education at frequent intervals (figure 2). Details of each step in the PDSA were the following: (1) We planned for the education sessions by developing the process, materials and education evaluation forms based on learning outcomes and grant-designated goals. (2) We carried out the education by implementing our plan. (3) We studied the collated evaluation feedback consisting of written and verbal comments from participants, educators and grant team facilitators following each education session, presented at monthly grant team meetings. (4) We acted on the evaluation information by changing the education process or materials with agreed on revisions. The evaluations informed the effectiveness of our education and became input into revisions in the next PDSA cycle where we repeated the process after each education session. We assessed our progress towards grant-designated goals every month at grant team meetings and considered quality changes as a collaborative team. We summarised each step in the education model, changes made based on PDSA and mapping of each step to the IPEC core competencies in table 1 .

\section{Didactic}

We designed the first step in our education model to address knowledge acquisition via online didactic content delivery. Establishing common knowledge is an important design component of IPE so that all disciplines possess a mutual baseline. We created a $30 \mathrm{~min}$ online narrated slideshow module organised into major topics based on the American Geriatrics Society clinical practice guidelines recommended for a comprehensive approach to reducing falls risk. ${ }^{8}$ A second 30 min module was created based on TeamSTEPPS curriculum concepts. ${ }^{3}$ Pharmacy, advanced practice nurses and medical students were also assigned an additional 20 min module that included specifics for their professions. Audio and visual components were embedded along with case study scenarios, and knowledge-check questions to increase learning and interactivity. Students were required to view these recordings as preparation for the remaining steps of the education. Participant compliance with this phase in the second year was $84 \%$.

\section{Posters/skills practice}

The second step of our education model, skills posters, was designed to reinforce the knowledge gained in the online didactic by incorporating interactive skills practice. In speed-dating fashion, students rotated in primarily single-profession groups when possible (not interprofessional at this point) to six different stations 
Table 1 Education steps, lessons learnt and IPEC Core Competency mapping

\begin{tabular}{|c|c|c|c|}
\hline Education step & Description & Lessons learnt: QI Revisions & $\begin{array}{l}\text { IPEC Core } \\
\text { Competency }^{7}\end{array}$ \\
\hline Didactic & $\begin{array}{l}\text { Online narrated slides with content related to } \\
\text { geriatric falls risk assessments and interventions, } \\
\text { and TeamSTEPPS teamwork concepts. }\end{array}$ & $\begin{array}{l}\text { Length decreased from } 2 \text { hours } \\
\text { to } 1 \text { hour; supplemental slides for } \\
\text { medicine and pharmacy. }\end{array}$ & $\begin{array}{l}\text { VE } \\
\text { RR } \\
\text { CC } \\
\text { TT }\end{array}$ \\
\hline $\begin{array}{l}\text { Posters/Skills } \\
\text { practice }\end{array}$ & $\begin{array}{l}\text { Visual display of focused didactic points with } \\
\text { hands-on skills practice. Topics included } \\
\text { environmental factors, nutrition, cognition, } \\
\text { pharmacology, mobility and TeamSTEPPS. Short } \\
\text { encounters with each topic facilitated in small } \\
\text { groups. }\end{array}$ & $\begin{array}{l}\text { Time at each poster was lengthened to } \\
8-9 \text { min. Small groups were changed } \\
\text { from interprofessional to single } \\
\text { professional. Presentations were } \\
\text { standardised for active learning focus. }\end{array}$ & $\begin{array}{l}\text { VE } \\
\text { RR } \\
\text { CC } \\
\text { TT }\end{array}$ \\
\hline $\begin{array}{l}\text { Presimulation } \\
\text { discipline huddles }\end{array}$ & $\begin{array}{l}\text { Single professional groups receive report on a } \\
\text { complex geriatric simulation patient. Profession- } \\
\text { specific assessments, goals and interventions are } \\
\text { planned over } 10 \text { min with a facilitator. }\end{array}$ & $\begin{array}{l}\text { Original format was to require students } \\
\text { to request information. Revision to } \\
\text { providing details to meet time limits } \\
\text { and allow time for planning. }\end{array}$ & $\begin{array}{l}\text { VE } \\
\text { RR } \\
\text { CC }\end{array}$ \\
\hline $\begin{array}{l}\text { Volunteer patient } \\
\text { assessments and } \\
\text { care planning }\end{array}$ & $\begin{array}{l}\text { Interprofessional student teams conduct a falls risk } \\
\text { assessment (under the supervision of practitioners } \\
\text { from our Falls clinic) on a volunteer older adult. } \\
\text { Coordination of the assessment among team } \\
\text { members and interaction with the patient are goals } \\
\text { to reveal a patient-centred plan. }\end{array}$ & $\begin{array}{l}\text { This component of the education } \\
\text { was added in the second year to help } \\
\text { students transition education into } \\
\text { practice. Time was lengthened from } 40 \\
\text { to } 50 \text { min. }\end{array}$ & $\begin{array}{l}\text { VE } \\
\text { RR } \\
\text { CC } \\
\text { TT }\end{array}$ \\
\hline $\begin{array}{l}\text { Expert team } \\
\text { feedback }\end{array}$ & $\begin{array}{l}\text { The patient-centred plan developed for the } \\
\text { volunteer assessed is shared with a panel of experts } \\
\text { for feedback. Each team has } 10 \text { min to present their } \\
\text { case and plan for feedback. }\end{array}$ & $\begin{array}{l}\text { Minor adjustments decreased time to } \\
10 \text { min for each team to present to a } \\
\text { panel of experts. }\end{array}$ & $\begin{array}{l}\text { VE } \\
\text { RR } \\
\text { CC } \\
\text { TT }\end{array}$ \\
\hline
\end{tabular}

CC, interprofessional communication, IPEC, Interprofessional Education Collaboration; RR, roles/responsibilities; TT, teams/teamwork; VE, value/ethics

lasting 6-7 min. Each station offers a visual display poster of information that paralleled online didactic content, and a facilitator to guide them through important points

Table 2 Skills practice poster stations

\begin{tabular}{|c|c|}
\hline Major topic & $\begin{array}{l}\text { Assessment tools and } \\
\text { interactive skill(s) }\end{array}$ \\
\hline Cognitive assessment & $\begin{array}{l}\text { Mini-Cog screen, Depression } \\
\text { screen (PHQ-9) }\end{array}$ \\
\hline Medication assessment & Medication review for falls risk \\
\hline Mobility assessment & $\begin{array}{l}\text { Timed Up and Go test, } \\
\text { Strength and balance } \\
\text { evaluation }\end{array}$ \\
\hline Nutrition assessment & $\begin{array}{l}\text { Nutrition screening tool, grip } \\
\text { strength measurement }\end{array}$ \\
\hline Environment assessment & $\begin{array}{l}\text { Search pictures for } \\
\text { environmental risk activity }\end{array}$ \\
\hline TeamSTEPPS & $\begin{array}{l}\text { TeamSTEPPS communication } \\
\text { interactive game }\end{array}$ \\
\hline
\end{tabular}

and interactive skills practice related to the topic. Poster topics and activities are summarised in table 2.

\section{Interprofessional team simulation}

Building on knowledge and skills acquisition from the first two steps, the third step of our education model is an interprofessional team meeting simulation. This table-top case study simulation is based on a real-life complex geriatric patient with multifactorial falls risk factors and a history of falls, embellished to include details that would have relevancy to all professions attending the training.

Students begin with a $10 \mathrm{~min}$ pre-brief patient hand-off report, gathering case details in single-profession huddles. The basic facts are provided to all professions, but additional case details are given that are specific to each discipline to mimic a real-life professional handoff report. For example, only nursing students are given details about orthostatic blood pressures since this is a nursing assessment. Huddle facilitators assist students to process the information and determine priorities and interventions to be shared in the interprofessional meeting from their professional standpoint. 
Following the discipline huddle, students gather in interprofessional teams of $6-8$ with a facilitator to discuss the patient case. Using a standardised script, facilitators begin the exercise by clarifying expectations and leading the group to work through the first patient problem (such as complaints of dizziness). After modelling the problem-solving process in the first problem, facilitators then hand over leadership of the meeting to the students to work through the remaining risk factors in a similar fashion. The expectation of the facilitator's role after working through the first problem is to interject only if the group became stuck on how to proceed or to engage professions that do not participate in the care plan discussion. A case summary is provided to facilitators that contains all assessment findings for each fall risk factor for each profession. This summary is used to provide cues as needed and to ensure consistency across groups.

A second facilitator may be assigned the role of TeamSTEPPS facilitator. This person plays the confederate role to disagree with decisions being made by the team. The purpose of this design feature is to give students the opportunity to practice dealing with team conflict using TeamSTEPPS communication strategies taught in the didactic and poster/skills session. These facilitators are provided scripted cues to contradict team decisions at certain points in the discussion. For example, when the team is discussing patient medications, this facilitator would interject, 'Let's just take her off of all of these medications and see if she does better.'. This is intended to trigger disagreement and allow students to use one of the TeamSTEPPS communication tools such as 2-challenge or CUS (Concern, Uncomfortable, Safety issue). ${ }^{9}$

Following the team meeting simulation (20 min), approximately $25 \mathrm{~min}$ is allotted for a small group debrief. To be consistent across groups, facilitators are given cues to guide debriefing based on the learning objectives and instructed on using debriefing with good judgement methods. ${ }^{9}$ Major debriefing points focus on geriatric concepts and teamwork. We intended to demonstrate how interconnected geriatric problems can be, and that by optimally managing one problem, there may be an impact on another. Teamwork skills would be debriefed such as communication across professional lines, the use of TeamSTEPPS communication tools, leadership, attitude of respect for others, collaboration and inclusion.

\section{Volunteer assessments and care planning}

The fourth step of our education model is performing an interprofessional team falls risk assessment on an older adult, who has fallen or is at high risk for falls. This is followed by the students' team development of a patient-centred plan of care. We designed this step to reinforce the knowledge and skills of the previous steps to transition into actual clinical practice. We recruited older adults at risk for falls from the community on a voluntary basis and informed them of the educational purpose of the exercise. Each interprofessional team is given $30 \mathrm{~min}$ to perform a standardised falls risk assessment on their volunteer under the supervision of experienced clinicians and faculty. The assessment form used is adapted from our Falls Risk Reduction Clinic and includes medical and medication history and objective physical assessments. A licensed pharmacist reviews each of our volunteer's medications and provides recommendations to the teams regarding medication issues that raise falls risk. Falls risk findings revealed in the assessment are communicated to volunteers in writing, and they are encouraged to share them with their primary care provider. In addition, a referral to the Falls Risk Reduction Clinic for follow-up is offered when appropriate, and volunteers are given a general falls risk reduction brochure for educational purposes.

\section{Expert team feedback}

The final step of this education model is team presentation of assessments and care planning to an expert panel consisting of clinicians and faculty. The purpose of this step is to provide experience in forming an interprofessional care plan and to receive immediate feedback and guidance from experts. Like simulation debriefing, this activity fosters student reflection on decisions and allows them to create accurate cognitive frames for future reference.

\section{METHODS}

\section{Subjects}

Health profession students from 12 different professions were recruited by educators of multiple professions at three different academic institutions for either voluntary experience or as a required part of coursework. Inclusion criteria were health profession students at any level and willingness to complete all steps of the education programme and demographic survey. Other than demographics, completion of pre-post measurement surveys was voluntary and not a requirement of education participation. Of the 237 student participants in year two of the grant, 205 completed the demographic data reported in frequencies and percentage of the total number in table 3. Age of the students in years was calculated with a mean age of 25.7 (SD 8.6) and range of 17-63.

\section{Setting}

We conducted our education at grant-partner academic institutions, hosting groups of 30-100 students at a single IPE event. We required a large classroom space to accommodate all participants for the introduction and final large group debriefing at the end of the training and the ability to create small group workspace for other components of the education.

\section{Procedures}

Our study was a mixed method one-group pretest, posttest design. Internal review board granted approval at each institution as exempt status. Our educators recruited health profession students for participation in this education programme focused on geriatric falls 


\begin{tabular}{|c|c|c|}
\hline Characteristic & Count & $\%$ \\
\hline \multicolumn{3}{|l|}{ Profession } \\
\hline Allied Health* & 105 & 56.1 \\
\hline Nursing & 63 & 33.7 \\
\hline Medicine & 10 & 5.3 \\
\hline Pharmacy & 9 & 4.8 \\
\hline \multicolumn{3}{|l|}{ Gender } \\
\hline Female & 149 & 72.3 \\
\hline Male & 57 & 27.7 \\
\hline \multicolumn{3}{|l|}{ Race } \\
\hline White & 163 & 79.5 \\
\hline Black or African American & 16 & 7.8 \\
\hline More than one race & 11 & 5.4 \\
\hline Asian & 9 & 4.4 \\
\hline Race not reported & 6 & 2.9 \\
\hline \multicolumn{3}{|l|}{ Age (years) } \\
\hline $17-26$ & 147 & 75.4 \\
\hline $27-41$ & 34 & 17.4 \\
\hline $42-63$ & 14 & 7.1 \\
\hline Total & 205 & \\
\hline
\end{tabular}

*Speech, physical, occupational therapies, nutrition, social work, counselling, chaplain, Emergency Medical Tech.

assessment and prevention. Our consent form explained to participants they would complete a demographic and pre-education baseline attitude survey, view a 1 hour online didactic slideshow for preparation, and come to a 3-4hour in-person education. Posteducation, there is a postattitude survey and an education satisfaction survey to complete. Students who agreed to participate granted informed consent electronically prior to accessing the pre-education didactic. We maintained anonymity on surveys using a coding system that allowed matching of pre-post surveys but not linked to an individual's identity.

\section{Outcome measure instruments}

We used the Interprofessional Socialization and Valuing Scale (ISVS) to measure student attitudes associated with interprofessional practice as a pretest before didactic, and post-test immediately following the education. Previous use of the ISVS in studies revealed good psychometrics in validity and reliability. ${ }^{10}$ The survey contains 24 statements that are rated on a 6 -point Likert scale $(1=$ Not at all, $2=$ To a very small extent, $3=$ To a small extent, $4=$ To a moderate extent, $5=$ To a great extent and $6=$ To a very great extent). We slightly reworded some of the pretest ISVS items to make them appropriate because this tool was designed for postintervention assessment in its original form. We assessed reliability of the ISVS with Cronbach's $\alpha$ for each of the three subscales measuring (1) Ability to function in teams, (2) Valuing of teamwork and (3) Comfort in practicing as part of a team and the total score. ${ }^{10}$ Alpha coefficients ranged from 0.786 to 0.935 with the lowest for the comfort subscale, which has only six items. Overall, the ISVS and its subscales demonstrated high reliability based on participants with complete pre-responses and post-responses $(n=137)$. Separate analyses were performed for the pretest and the post-test discussed in results.

We measured satisfaction with a researcher-created 12-item survey. Our instrument contains quantitative statements rated on a 5-point Likert scale and qualitative comments for each step of the education (didactic, poster/skills session, simulation case, volunteer assessment and care planning with feedback). There are also items for rating the most and least effective steps of the education, recommendations for future events and an open entry area for qualitative comments.

\section{Analysis}

Pretest scale scores would be compared with post-test scale scores using paired $t$-tests with an a priori $\mathrm{p}<0.05$ level of significance. Satisfaction surveys would be analysed by calculating a mean average score for each item and a mean total score of all items. Qualitative data would be analysed manually for common themes, grouped by key words and verified by three study investigators independently.

\section{RESULTS}

Students who were unable to complete all steps of the education, or who declined to complete both pretest and post-test ISVS surveys, were excluded from analysis. A total of 136 of the $237(57.4 \%)$ student attendees completed both the pre-ISVS and post-ISVS surveys during year two of the grant cycle. We computed ISVS subscale mean scores of the item responses that comprise the scales. ${ }^{10}$ Change scores were computed and confirmed for normality and symmetric distributions, but with higher central peaks than would be expected for a normal distribution. Although $t$-tests are robust against departures from normality, non-parametric Wilcoxon signed-rank tests were also carried out. These tests produced nearly identical results as the $t$-tests, so we decided to report the more familiar $t$-test results. Table 4 presents mean scores for each subscale of the ISVS, both for the pretest and the post-test, mean change scores and $\mathrm{p}$ values for the paired $t$-tests.

Higher subscale means indicate more positive attitudes towards working with professionals from other disciplines. Note that the Ability, Value and Total mean scores were initially fairly high even before the educational experience (means greater than 5 on a 6-point scale); Comfort was somewhat lower with a mean of about 4.5 on the pretest. Following the educational experience, mean scores increased for each subscale and the total scale, as indicated by the positive mean change scores in table 4 . The Ability scale, the Value scale, the Comfort scale and the Total scale each exhibited statistically significant increases. 
Table 4 ISVS analysis comparing pretest vs post-test scale scores and total score

\begin{tabular}{lcccc}
\hline Scale & Pretest mean (SE) & Post-test mean (SE) & $\begin{array}{l}\text { Mean change (SE) } \\
\text { (Post-Pre) }\end{array}$ & P values \\
\hline Ability & $5.17(0.052)$ & $5.34(0.043)$ & $0.17(0.050)$ & $<0.001$ \\
Value & $5.11(0.054)$ & $5.31(0.047)$ & $0.21(0.050)$ & $<0.001$ \\
Comfort & $4.48(0.065)$ & $4.61(0.071)$ & $0.21(0.050)$ & $<0.001$ \\
Total & $5.01(0.050)$ & $5.20(0.044)$ & $0.19(0.045)$ & $<0.001$ \\
\hline
\end{tabular}

ISVS, Interprofessional Socialization and Valuing Scale.

A second analysis of the ISVS change scores was conducted by grouping them into three categories: Increased, No Change and Decreased using the $\chi^{2}$ goodness-of-fit test. Compared with baseline scores, probability analysis revealed that $58 \%$ of the participants showed an increased overall score on the post-test, $24 \%$ showed no change and $18 \%$ scored lower with a statistically significant difference $(\mathrm{p}<0.0001)$.

Results of the qualitative analyses of the satisfaction survey are shown in table 5. Of the 237 attendees, 135 $(57 \%)$ contributed at least one written comment. All comments with four or more students responding similarly are included. Students may have written more than one comment per category, but all responses were recorded.

Comments were primarily positive with some negative comments noted. Most suggestions under the recommendations for future events item (other than stating 'none') were related to logistical issues of time, organisation and mix of professions. These suggestions confirm to educators that logistics are important to the learning experience, and our planning team used these concerns to improve the experience of future events through the PSDA model. Over half of those responding most valued the volunteer assessment step where they were able to apply what they learnt as a team to an actual person at risk for falls. The second most valued step was the team simulation exercise. These comments emphasise the students' valuing of these particular active forms of IPE learning.

\section{DISCUSSION}

Results of this study indicate that an active learning IPE model can result in positive outcomes for health profession students' attitudes regarding interprofessional teambased care and satisfaction with the learning experience. In addition to the quantitative results, the qualitative comments uncovered the overall success of this design and at each step of this scaffolded education model.

\section{Lessons learnt at each step}

By using a rapid cycle PDSA process in our programming, our team was able to make changes based on student and facilitator feedback to each step of the model to enhance the experience and learning potential for the students participating. For the readers interested in avoiding some of the pitfalls we encountered, we offer details of these lessons learnt, noted earlier in table 1.

Lessons learnt regarding the didactics were: (1) online accessibility, (2) keep it short, (3) make it interesting and interactive, (4) send out reminders and (5) plan for technical support. The challenge of online accessibility across different schools was a challenge we solved by purchasing a subscription to an online platform that permitted secure sharing of informed consent, didactics, schedules, learning objectives, surveys, directions and parking. An important lesson regarding the didactic was keeping it short and to the point. In our second year, we decreased from an original 200 slides narrated over 2 hours, to a condensed 112 slides lasting 1 hour in year two. We also designed a supplemental 20 min didactic for only medicine, advanced practice nurses and pharmacy students to provide details specific to them. Case scenarios, challenge questions, pictures and limited text were used to increase interest and interaction in the slide presentation. Lastly, we learnt that dedicated tech support was needed to build in automated student reminders, to make updates to the materials and to troubleshoot tech issues with students.

Lessons learnt regarding the poster/skills practice session: (1) Structure the rotation, (2) Single profession grouping, (3) Standardise presentation approach. Our original design of this step was to provide a 'skills fair' that allowed students to rotate to each station at will. We found that without structure, some students would mill about without engaging in meaningful learning, while others would spend most of the time at one or two stations thereby missing out on other topics. Our revision was to assign groups to a rotation schedule. We also decided to group students by profession rather than in interprofessional groups for skills posters, although this was not always possible. This design allowed the poster facilitators to focus according to each group's professional point of view, thus giving flexibility to increase or decrease the depth of the topic depending on the profession. For example, students in nutrition were given a different depth compared with pharmacy students at the pharmacy skills station and likewise for other topics. A final lesson learnt was that it is important to standardise among facilitators with a focus on interactive skill application. There can be wide variation in presentation techniques (eg, lecture only, presenting the perspective of one profession only) if this is not done. 


\section{Comment topic (Number of comments) \\ Online didactics and other educational materials $(n=117)$

Poster/Skills training posters $(n=135)$}

\section{Comment}

Beneficial/prepared us for the simulation

Easy to use/well done/organised

Too long/redundant

Not beneficial

Good review/good information/helpful

Need more time at each station

Crowded/too noisy/hard to read

Some better than others

To the point/quick

Good information/good case/informative

Realistic

Incorporated all team members/good to see what other bring/good to learn to work in team

Learnt a lot about falls prevention

Showed importance of team approach/learnt from other professions about interventions/good team

Enjoyed/good/helpful/valuable

Low risk volunteer not beneficial to learning

Need more organisation

Most beneficial part $(n=132)$

Volunteer portion/applying what we learnt/critical thinking

Working as a team

Simulation

Skill posters

Feedback/debrief/group discussion

None (actual response)

Better explanation of what will happen at event

Increase time for event, more time for volunteer interview

Ensure all groups have all professions represented

Stay on schedule

Increase space for posters

Other comments $(n=76)$

$\begin{array}{lc}\text { Great course/learnt a lot/good learning experience/informative/excellent/valuable/ } & 27 \\ \text { loved it/helpful/best team learning experience yet } & 10 \\ \text { Thank you } & 13 \\ \text { Pleased/enjoyable/fun/wonderful/glad I came } & 7 \\ \text { Good to work with other professions/makes me want to work in team setting } & 5 \\ \text { None (actual response) } & 4\end{array}$

*Note that students may have written more than one comment, and all comments were included.

Lessons learnt regarding the simulation step of the education model were mostly related to attention to the details: (1) Script words for facilitators to use, (2) Embed conflict opportunities. Grant team members serving as facilitators recognised the need to provide more standardisation to ensure that students were given similar experiences across groups. This led to scripting of how to start the simulation meeting as well as appropriate cues to provide during the simulation and debriefing phases. We also decided to integrate TeamSTEPPS challenges into the script because many of the simulations in the first year did not naturally lead to disagreement among 
team members which did not allow opportunity to use conflict resolution strategies with each other. We felt that offering this opportunity to practice conflict resolution in the safety of simulation would increase the likelihood of using these techniques effectively in real practice.

Lessons learnt regarding the volunteer assessment: (1) Add this step, (2) Organise the form by profession, (3) Ask volunteers to complete the history in advance and (4) Arrange for professional practitioners to supervise student teams. We added this step to the model in our second year to provide opportunity for students to transfer what was recently learnt into actual practice. We learnt that organising the assessment form by professional blocks increased efficiency, and asking the volunteers to complete the history section in advance helped stay within our timeframe. Qualitative feedback from students was strongly positive and we have continued to make it a standard part of the education model.

Lessons learnt regarding the expert team feedback have been minor since adding it to the model in year two. Mainly, we adjusted the time allowed for this feedback to fit with the overall time of the event. We identified that each team had to be held to a time limit of $10-15$ min each to allow all teams to receive the same amount of feedback.

\section{Study limitations}

There were a few threats of bias related to internal validity in this study. First, we used convenience sampling methods which would limit generalisability of the results. From a practical position, it is not reasonable to conduct randomisation in education research, therefore replication of this study with other participants from different mixes of professions and settings can add strength to the evidence produced in this study. Also, the effect of administration of the pretest may have influenced the post-test results as a testing threat of internal validity. We feel this threat was minimised by also collecting qualitative comments that supported the quantitative data results. Also, missing data related to a $57 \%$ response rate on the pretest and posttest surveys offer a potential threat for skewed results. However, there is no evidence that the results were effected in a positive or negative manner. Last, there may have been an inconsistency among facilitators during the poster skill stations and team simulations that could influence student experience and outcomes. To address this limitation, we plan to video-record each step for future events to standardise presentations.

\section{Recommendations for future studies}

Falls requires an interprofessional approach for optimal management, yet students are ill prepared to function in teams that are focused on chronic long-term geriatric syndromes. This simulation method was shown to be both enjoyable and effective at improving interprofessional competencies for groups of interprofessional learners. The simulation methodology requires no special equipment and can be conducted in a classroom setting.
Although the subject matter in this simulation concerned falls prevention, our model is easily replicable and is generalisable to a number of geriatric syndromes.

IPE has become a mandated requirement in many health profession curriculum as part of accreditation criteria. Because of this requirement, educators are pressed to develop or adopt learning models to be compliant, and good choices need to be made to move students towards interprofessional collaborative competencies. IPE should not just be a box to check off, but should be the result of careful consideration for a positive learner experience and intentional building of interprofessional collaborative competencies. If IPE does not enhance a positive attitude towards teamwork among different health professions, it has missed the mark. The knowledge, skills and attitudes of interprofessional collaborative competencies should serve as a guide in curriculum planning and include mapping of experiences to these competencies. ${ }^{7}$

\section{Author affiliations}

${ }^{1}$ College of Health Professions, The University of Akron, Akron, Ohio, USA ${ }^{2}$ College of Pharmacy, Northeastern Ohio Medical University, Rootstown, Ohio, USA

${ }^{3}$ Department of Pharmacy, Summa Health, Akron, Ohio, USA

${ }^{4}$ School of Health Sciences, Cleveland State University, Cleveland, Ohio, USA

${ }^{5}$ Seniors Institute Research, Summa Health System, Akron, Ohio, USA

${ }^{6}$ Emergency Medicine, Academic and Community Emergency Specialists, Uniontown, Ohio, USA

${ }^{7}$ Senior Health, Summa Health System, Akron, Ohio, USA

${ }^{8}$ Family and Community Medicine, Northeastern Ohio Medical University, Rootstown, Ohio, USA

${ }^{9}$ School of Social Work, Cleveland State University, Cleveland, Ohio, USA

${ }^{10}$ School of Nursing, Cleveland State University, Cleveland, Ohio, USA

${ }^{11}$ School of Counseling, The University of Akron, Akron, Ohio, USA

${ }^{12}$ Planning and Quality Improvement, Direction Home Area Agency on Aging and Disabilities, Akron, Ohio, USA

${ }^{13}$ Department of Statistics, The University of Akron, Akron, Ohio, USA

${ }^{14}$ Summa Health System, Akron, Ohio, USA

${ }^{15}$ Family Medicine, Summa Health System

${ }^{16}$ Emergency Medicine, Summa Health System, Akron, Ohio, United States

Acknowledgements We would like to acknowledge the contributions of all grant team members who aided in the design and implementation of this project including Michele Gareri, Amanda Harvan, Kristin Lehotsky, Everett Logue, Kim Peterson, Carol Powell, Dr Edward Scott, Craig Sisak, Brian Tritchler, Carrie Wissmar, Michelle Boltz, Nancy Harris and Rita Young.

Contributors DKB contributed to the design of the study, education, implementation and writing the original draft of this manuscript. SH was the project manager of the grant and planned the study, contributed to the design, education, implementation and assistance with reporting of the work. The following contributed to the education design, implementation and editorial writing of the results: SF, MW, CM, JCD, JEN and RP. DJK contributed to statistical analysis. RPS contributed to statistical analysis and reporting of results. CAH, AM, EF, EDS and FO-F contributed to education design and implementation.

Funding This project is supported by the Health Resources and Services Administration (HRSA) of the US Department of Health and Human Services (HHS) under grant number UD7HP28539 entitled Nurse Education Practice Quality and Retention Program for $\$ 484476$ year two.

Disclaimer This information or content and conclusions are those of the author and should not be construed as the official position or policy of, nor should any endorsements be inferred by HRSA, HHS or the US Government.

Competing interests None declared.

Patient consent Not required. 
Ethics approval Summa Health System.

Provenance and peer review Not commissioned; externally peer reviewed.

Data sharing statement There are no unpublished data available from this study.

Open access This is an open access article distributed in accordance with the Creative Commons Attribution Non Commercial (CC BY-NC 4.0) license, which permits others to distribute, remix, adapt, build upon this work non-commercially, and license their derivative works on different terms, provided the original work is properly cited, appropriate credit is given, any changes made indicated, and the use is non-commercial. See: http://creativecommons.org/licenses/by-nc/4.0/.

\section{REFERENCES}

1. Kohn L, Corrigan J, Donaldson M, eds. To err is human: building a safer health system: National Academies Press, 2000.

2. Goodman RA, Posner SF, Huang ES, et al. Defining and measuring chronic conditions: imperatives for research, policy, program, and practice. Prev Chronic Dis 2013;10:E66.

3. Agency for Healthcare Research and Quality. TeamSTEPPS Instructor Guide 2.0. 2014. https://www.ahrq.gov/teamstepps/instructor/ fundamentals/index.html (Retrieved Apr 2018).
4. Reeves S, Palaganas J, Zierler B. Synthesis of Interprofessional Education (IPE) reviews. Measuring the impact of interprofessional education on collaborative practice and patient outcomes. Washington DC: National Academies of Sciences, 2015:93-100.

5. Decker S, Fey M, Sideras S, et al. Standards of best practice: simulation standard VI: the debriefing process. Clin Simul Nurs 2013;9:S26-S29.

6. Benner P, Sutphen M, Leonard V, et al. Book highlights from educating nurses: a call for radical transformation: Carnegie Foundation Archive eLibrary, 2010.

7. Interprofessional Education Collaborative. Core competencies for interprofessional collaborative practice: 2016 update. Washington D.C.: Interprofessional Education Collaborative.

8. American Geriatrics Society. AGS/BGS Clinical practice guideline: prevention of falls in older persons. 2010. http://www. americangeriatrics.org/health_care_professionals/clinical_practice/ clinical_guidelines_recommendations/prevention_of_falls_sum

9. Rudolph JW, Simon R, Dufresne RL, et al. There's no such thing as "nonjudgmental" debriefing: a theory and method for debriefing with good judgment. Simul Healthc 2006;1:49-55.

10. King G, Shaw L, Orchard CA, et al. The interprofessional socialization and valuing scale: a tool for evaluating the shift toward collaborative care approaches in health care settings. Work 2010;35:77-85. 